\title{
Diagnóstico de la situación del portal de turismo Cubatravel para la promoción del destino Cuba.
}

DOI: https://doi.org/10.33262/ap.v3i3.2.96

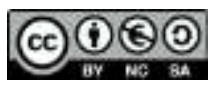

Diagnosis of the Cubatravel tourism portal situation for the promotion of the destination Cuba.

Yenifer Calderín Mayo. ${ }^{1}$ \& Luis Efraín Velastegui López. ${ }^{2}$

\begin{abstract}
The Ministry of Tourism of Cuba (MINTUR) has a tourism portal, Cubatravel, for the promotional communication of the destination $\mathrm{Cuba}$, which requires an improvement process since it does not meet many of its users' expectations regarding the quality of information and promotional efficiency. This research is intended to diagnose the current situation of the Cubatravel tourism portal, which contributes to the detection of the factors that are affecting the dissatisfaction of users in as for its functionality for the promotion of the territory. The diagnosis is divided into two phases, the determination of the correspondence of the portal with the best practices in web design of Caribbean tourist destinations and the evaluation of its web quality related to the promotion. The methods of this study include the CODETUR project analysis methodology, as well as web analysis tools such as Woorank, Gt Metrix, Alexa, Nibbler, Site worth Traffic, Cynthia Says and Alexa Rank Checker Sinium. Among the main results, the portal requires positioning keywords that correspond to the official names of the different tourist destinations, reducing their loading speed and page size, as well as improving their interaction with users to achieve their confidence.
\end{abstract}

Keywords: Tourism portal, Cubatravel, promotion, web quality.

\section{Resumen}

El Ministerio de Turismo de Cuba (MINTUR) cuenta con un portal de turismo, Cubatravel, para la comunicación promocional del destino Cuba, el cual requiere un

${ }^{2}$ Ciencia Digital Editorial, Ecuador, luisefrainvelastegui@cienciadigital.org 
proceso de perfeccionamiento puesto que no cumple con muchas de las expectativas de sus usuarios en cuanto a la calidad informativa y eficacia promocional. La presente investigación tiene el propósito de diagnosticar la situación actual del portal de turismo Cubatravel, lo que contribuye a la detección de los factores que están incidiendo en la insatisfacción de los usuarios en cuanto a su funcionalidad para la promoción del territorio. El diagnóstico se divide en dos fases, la determinación de la correspondencia del portal con las mejores prácticas en diseño web de destinos turísticos del Caribe y la evaluación de su calidad web relacionado con la promoción. Los métodos de este estudio incluyen la metodología de análisis del proyecto CODETUR, así como herramientas de análisis web como, Woorank, Gt Metrix, Alexa, Nibbler, Site worth Traffic, Cynthia Says y Alexa Rank Checker Sinium. Entre los principales resultados el portal requiere posicionar palabras clave que se correspondan con los nombres oficiales de los diferentes destinos turísticos, disminuir su velocidad de carga y tamaño de páginas, además de mejorar su interacción con los usuarios para alcanzar la confianza de los mismos.

Palabras Clave: Portal de turismo, Cubatravel, promoción, calidad web.

\section{Introducción}

El sector turístico es intensivo en información, por lo cual ha hecho uso de las Tecnologías de la Información y las Comunicaciones (TICs) como pocos otros (Díaz y López, 2012). El desarrollo de Internet como forma universal e interactiva de comunicación ha modificado, al igual que las actitudes y comportamiento de los consumidores, la forma tradicional de distribución de los productos turísticos (Verdecia, 2018). Internet se ha convertido en una herramienta indispensable en la fase de planificación y desarrollo del viaje, así como en uno de los canales principales para la comercialización de un destino turístico (Martínez et al., 2017).

Las tecnologías de la información, constituyen un cambio en el concepto de vida de las personas, donde el usuario adquiere un gran protagonismo, dejando de ser consumidor para convertirse en evaluador, crítico y generador de contenidos relacionados al productoservicio recibido a través de los canales de la web 2.0 (Córdova y Freixa, 2017). El turista 2.0 alude a un viajero informado y participativo que ya no decide exclusivamente a partir del consejo de una agencia de viajes sino de toda la información que recopila de Internet. Es precisamente la necesidad informativa lo que ha convertido los sitios webs en un instrumento clave para la comunicación de los destinos turísticos (Martínez et al., 2017). A ello se suman la multitud de redes sociales o servicios OSN (Online Social Networking) que son ya una realidad para que las empresas se promocionen, en especial para el sector turístico, en ellas los propios usuarios hacen comentarios de sus viajes y manifiestan sus opiniones. Aunque, el primer paso esperable para que una empresa o destino esté presente en Internet es la creación de su página web (Araujo et al., 2019).

Los sitios web de un destino o empresa turísticos juegan un papel esencial en el desempeño de las autoridades u organizaciones responsabilizadas con los mismos, como es el caso de las Organizaciones de Marketing de Destinos (OMDs) en los temas de 
promoción, marketing, y comercialización del producto turístico y los servicios a él asociados (Salgado, 2009); integrándose las estrategias de comunicación del destino tanto en el sitio web como en las plataformas sociales en las que tiene presencia (Tapia, 2015), enfocándose en la interactividad que permita alcanzar el interés y la participación de los turistas (Ogra, 2014). El hecho de tener un sitio web no es en sí mismo garantía del éxito, los sitios web de los destinos deben ser sometidos a evaluación periódica para garantizar tanto su calidad como el éxito de su misión para dar respuesta al turista en el nuevo contexto (Sanabre et al., 2019).

Las tecnologías y el gran impacto de estas en el sector turístico han propiciado que la calidad web haya tomado una gran relevancia, puesto que la información que va reuniendo el usuario y posible cliente a través de Internet repercute enormemente a la hora de crear su propia imagen de la marca, la empresa y de los productos que ésta oferta. Es por ello, que han surgido diversas herramientas de análisis de la calidad de un sitio web, que evalúan características tales como: la accesibilidad; la velocidad; la usabilidad y navegabilidad; y la calidad del contenido (Cáceres, 2016).

En el caso particular de Cuba una de las principales Organización de Marketing de Destinos (OMDs) es precisamente el Ministerio de Turismo de Cuba (MINTUR). Dicha entidad cuenta con un portal de turismo, Cubatravel, para la comercialización del destino Cuba, el cual fue sometido a un proceso de actualización en el 2017, pero aún requiere un proceso de perfeccionamiento teniendo en cuenta las funcionalidades en lo referente a calidad web de los sitios de los destinos internacionales mejor posicionados. Aunque el departamento de informatización del MINTUR está trabajando en base a ello, las deficiencias aún persisten, lo que se expresa en la insatisfacción de sus usuarios al no cumplir con muchas de sus expectativas en cuanto a la calidad informativa y eficacia promocional, afectándose, incluso, la imagen del destino turístico cubano. Por todo ello se ha determinado la siguiente pregunta de investigación: ¿Cuáles son los factores que están incidiendo en la insatisfacción de los usuarios en cuanto a la funcionalidad del portal de turismo Cubatravel para la promoción del territorio? De acuerdo a lo anterior la presente investigación se plantea como objetivo diagnosticar la situación del portal de turismo Cubatravel para la promoción del destino Cuba.

\section{Metodología}

La investigación se estructuró de la siguiente forma:

1. Análisis de las metodologías existentes para la evaluación de sitios web

2. Diagnóstico

- Determinación de la correspondencia del portal con las mejores prácticas en el diseño web de destinos turísticos del Caribe

- Evaluación de la calidad web del portal de turismo Cubatravel

- Resultados del diagnóstico

3. Validación de la metodología 


\section{Análisis de las metodologías existentes para la evaluación de sitios web}

Durante la investigación se analizaron 4 metodologías desarrolladas en los años 2009, 2012, 2014 y 2017, que permiten medir de manera objetiva a través de varios parámetros e indicadores si la web alcanza unos niveles mínimos exigidos de calidad:

$\checkmark$ Metodología 1: Salgado (2009) define una guía general para la evaluación de sitios web de carácter turístico en su libro "El negocio electrónico en el turismo". Se establecen 100 indicadores agrupados en 5 parámetros fundamentales: página inicial, información sobre el destino, características del sitio web, organización interactiva de viajes, reservas/compras en línea.

$\checkmark$ Metodología 2: Propuesta de metodología presentada en la Revista Española de Documentación Científica como: "Indicadores para la evaluación de la calidad en cibermedios: análisis de la interacción y de la adopción de la Web 2.0”, donde Rodríguez-Martínez, Codina y Pedraza-Jiménez (2012) proponen un método de evaluación que establece dimensiones, parámetros e indicadores para la exploración de sitios web del ámbito de la comunicación con el fin de conocer si han hecho o no una adaptación adecuada al entorno de la web.

$\checkmark$ Metodología 3: El proyecto Comunicación Online de los Destinos Turísticos (CODETUR) desarrollado entre los años 2013 y 2014 por un equipo investigador bajo la dirección de José Fernández Cavia, que desarrolló un instrumento de evaluación integrada de la eficacia de sitios web, dispositivos móviles y web social. La metodología define 127 indicadores que se agrupan en 12 parámetros fundamentales: páginas de inicio, calidad y cantidad del contenido, arquitectura de la información, usabilidad y accesibilidad, comunicación móvil, posicionamiento, idiomas, tratamiento de la marca, interactividad, web social, distribución o comercialización y análisis discursivo (texto e imagen).

$\checkmark$ Metodología 4: "Validación de una metodología de evaluación de calidad de sitios web: caso de estudio UTMACH"; Vega, Celleri y Maza (2017) presentan los siguientes parámetros de evaluación: funcionalidad, eficiencia del desempeño, portabilidad, seguridad, usabilidad, compatibilidad, todos ellos basados en el estándar ISO/IEC 25010; además de SEO, un parámetro sobre la optimización en motores de búsqueda.

La selección de la metodología a aplicar en la investigación se hizo sobre la base de los siguientes criterios: diseño especializado en sitios web de destino turístico, multiplicidad de parámetros e indicadores, simplicidad de los indicadores, escalas de medida sencillas y análisis a profundidad. De las 4 metodologías analizadas cumplían con todos los criterios de selección la guía general para la evaluación de sitios web de carácter turístico de Salgado (2009) y el proyecto Comunicación Online de los Destinos Turísticos (CODETUR). De estas metodologías se seleccionó el CODETUR por tener mayor variedad de parámetros e indicadores, además de ser más actual dado que fue desarrollada en el 2014. 
Por otro lado, las herramientas de análisis web permiten medir los resultados de sitios web, para conocer las debilidades y/o fortalezas de los mismos y optimizarlos en consecuencia. Estas ofrecen una evaluación rápida, donde los datos ofrecidos a menudo no son exactos, recomendándose la utilización de varias de estas herramientas. Las herramientas de análisis web utilizadas en la investigación se seleccionaron sobre la base de varios criterios: posibilidad de acceso, disponibilidad de versión gratuita, no requiere suscripción obligatoria, presentación de los resultados clara, no requiere instalación y configuración y diversidad de parámetros a evaluar. De las 28 herramientas sometidas a criterio de selección, se seleccionaron finalmente, las herramientas Site worth Traffic, Cynthia Says, Alexa Rank Checker Sinium, Gt Metrix, Woorank y Alexa. También se seleccionó Nibbler, que es una herramienta online que solo permite analizar 5 páginas en su versión gratuita, al no ser posible dentro de los límites de la investigación la utilización de una versión pagada, se consideró la utilización de la gratuita, definiendo los resultados de análisis de 5 páginas como suficientes para hacerse una idea general del funcionamiento del sitio.

\section{Diagnóstico}

- Determinación de la correspondencia del portal con las mejores prácticas en el diseño web de destinos turísticos del Caribe

La determinación de la correspondencia del portal con las mejores prácticas en diseño web de destinos turísticos del Caribe se llevó a cabo a través de un estudio de Benchmarking, para ello se definieron primeramente las tendencias y buenas prácticas en diseño web a nivel internacional, las nuevas tendencias a través de la revisión de la bibliografía existente sobre el tema listándose las tendencias que presentaron coincidencias entre las fuentes utilizadas y esta lista preliminar se corroboró aplicando una entrevista no estructurada a la doctora Lisandra Torres, especialista en la temática objeto de estudio. Para la determinación de buenas prácticas en diseño web a nivel internacional se analizó el estudio "Buenas prácticas para el desarrollo digital del destino turístico cubano", llevado a cabo por el Ministerio de Turismo de Cuba, específicamente por Pavel Pavón Vargas en el 2018, como parte del proceso de actualización del portal de turismo Cubatravel.

Posteriormente se identificaron los destinos turísticos de la región del Caribe que, dada la cantidad de visitantes que reciben, constituyen competencia para el destino Cuba; para lo cual se utilizaron los datos del Barómetro del Turismo Mundial en su versión de enero de 2019. Se analizó el posicionamiento de los sitios web oficiales de los destinos de la competencia identificados. La herramienta online Site Worth Traffic permitió identificar los visitantes y visitas anuales a los sitios, y Alexa Rank Checker de la plataforma Sinium determinó el ranking global y regional de los mismos, es decir la posición que ocupan entre los sitios más visitados del mundo. Se utilizó el análisis comparativo de la herramienta GT Metrix para determinar la velocidad de carga de los mismos, se identificaron las principales palabras claves que tienen posicionadas dichos sitios con la ayuda de Alexa. La comparación se basó en los siguientes criterios: tendencias y buenas 
prácticas en diseño web, velocidad de carga, palabras clave posicionadas que generan tráfico al sitio.

\section{- Evaluación de la calidad web del portal de turismo Cubatravel}

Para el análisis de calidad del portal se combinó la metodología de análisis del proyecto Comunicación Online de los destinos Turísticos (CODETUR) 2014 con las herramientas de análisis y evaluación web GT Metrix, Nibbler y Woorank. La evaluación se realizó sobre la base de los parámetros páginas de inicio, calidad y cantidad de contenido, arquitectura de la información, usabilidad y accesibilidad, posicionamiento, idiomas, tratamiento de la marca, interactividad, web social y comunicación móvil, los cuales fueron tomados del CODETUR; además se incluyó el parámetro velocidad de carga tamaño de página para un total de 11 parámetros a evaluar. Cada parámetro fue medido a través de indicadores, tomándose en cuenta los sistemas de evaluación individual:

$\checkmark$ La plantilla de análisis del Proyecto CODETUR 2014 establece diversas escalas; solo se tomaron 0-1-2(mal, regular, bien) y 0-1(no, sí).

$\checkmark$ Gt Metrix realiza dos evaluaciones, la velocidad de carga y el peso de la página. La media de carga de un sitio web en la actualidad es de 4,9 segundos y el peso promedio o tamaño de la página, teniendo en cuenta un estudio reciente de Soasta, debe ser superior a $2 \mathrm{MB}$ en línea con las tendencias actuales de la web (Palmira,2019),

$\checkmark$ Nibbler asigna una puntuación de 0 a 10

$\checkmark$ Woorank establece tres criterios principales: correctos, a mejorar y errores, para los cuales se creó la escala 0 (errores), 1(a mejorar) y 2 (correctos).

A efectos de la presente investigación para alcanzar una evaluación final, se tomaron los valores referenciales que muestra la Tabla 1 , según los criterios de evaluación propios de cada herramienta.

\begin{tabular}{llll}
\hline Herramientas & \multicolumn{3}{l}{ Valores referenciales } \\
\cline { 2 - 4 } & Críticos & Aceptables & Óptimos \\
\hline CODETUR $^{1}$ & $\mathrm{x}<0.75$ & $0.75 \leq \mathrm{x}<1.75$ & $1.75 \leq \mathrm{x} \leq 2$ \\
Velocidad de carga $^{2}$ & $\mathrm{x}>5$ & $2<\mathrm{x} \leq 5$ & $\mathrm{x} \leq 2$ \\
Tamaño de página $^{3}$ & $\mathrm{x}>3$ & $2.30<\mathrm{x} \leq 3$ & $\mathrm{x} \leq 2.30$ \\
Nibbler $^{4}$ & $\mathrm{x}<3$ & $3 \leq \mathrm{x} \leq 8$ & $8<\mathrm{x} \leq 10$ \\
Woorank $^{5}$ & $\mathrm{x}<0.5$ & $0.5 \leq \mathrm{x}<1.5$ & $1.5 \leq \mathrm{x} \leq 2$
\end{tabular}

$1 \overline{45}$ A partir de la medición realizada se promediaron los indicadores por temática analizada.

${ }^{23}$ Se realizaron 4 análisis iguales y se calculó la media de los resultados

Tabla 1. Valores referenciales por herramientas aplicadas

Fuente: Elaboración propia. 
En el caso del parámetro usabilidad y accesibilidad, el indicador calidad de las imágenes se corroboró con la herramienta GT Metrix, y los indicadores etiquetas de texto alternativo y niveles de adecuación de accesibilidad se analizaron a través de la herramienta Cynthia Says. Para el análisis del parámetro posicionamiento se consultaron algunos datos de la herramienta Google Analytics facilitados por Yasmina Giro especialista en la administración del portal Cubatravel.

\section{- Resultados del diagnóstico}

Se diagnosticó la situación del portal Cubatravel a partir de la síntesis de los resultados de las fases anteriores en un diagrama de Ishikawa de 8 ramas, en el que se plasmaron los principales factores que inciden en la insatisfacción de los usuarios con respecto a la funcionalidad del portal para la promoción del destino Cuba.

\section{Validación de la metodología}

El diseño metodológico de la investigación fue validado por expertos que fueron sometidos a un proceso de autoevaluación de sus conocimientos relacionados con la temática objeto de estudio, mediante la aplicación de un cuestionario para determinar su nivel de experticia. Para ello se aplicó la Metodología para determinar el coeficiente de competencia del experto propuesta por el Comité Estatal para la Ciencia y la Técnica de la antigua URSS. Esta plantea que el coeficiente K, se calcula por la expresión, $K=1 / 2$ $(\mathrm{Kc}+\mathrm{Ka})$. Se seleccionaron 9 expertos cuyo Coeficiente de competencia K se encontraba entre 0.8 y 1, estos fueron: Ing. Osvaldo Sánchez Arenas, D.Sc. Lisandra Torres Hechavarría, D.Sc. Alejandro Delgado Castro, MS.c. Martha Omara Robert, D.Sc. Yasser Vázquez Alfonso, Técn. Pedro Alejandro Cruz Pérez, MS.c Ramón Pomes Hernández, Ing. Evelio González Fornaris y la MS.c Yasmina Giro Domenech.

\section{Resultados}

\section{Determinación de la correspondencia del portal con las mejores prácticas en el diseño web de destinos turísticos del Caribe}

El destino Cuba se encuentra entre los destinos turísticos del Caribe con más llegadas de turistas internacionales. Por otra parte, los destinos turísticos México, República Dominicana, Colombia, Puerto Rico, Costa Rica, Jamaica, Panamá, Nicaragua, Guatemala, Bahamas y Aruba constituyen sus principales competidores dadas las cifras de visitantes que reciben anualmente. Estos destinos turísticos cuentan con sitios web o portales oficiales que son: Visitmexico.com, Godominicanrepublic.com, Colombia.travel, Discoverpuertorico.com, Visitcostarica.com, Visitjamaica.com, Visitpanama.com, Visitnicaragua.com, Visitguatemala.com, Bahamas.com y Visitaruba.com.

El análisis realizado permite afirmar que los sitios mejor posicionados de la competencia en el Caribe son Bahamas.com, Colombia.travel, Godominicanrepublic.com y Visitmexico.com, puesto que son los que presentan mayor número de visitas y visitantes 
anuales, además del menor ranking tanto global como regional. Estos sitios presentan formatos de gran tamaño, texto e imágenes superpuestos y tienen videos e imágenes como fondos, utilizan la bitonalidad en cuanto al color y estos son brillantes, se emplean los espacios en blanco y presentan diseño responsive, cuentan con blog y emplean redes sociales. Los sitios de las Bahamas y República Dominicana destacan por la originalidad de sus mapas, al ser interactivos. Los sitios promocionan los productos y servicios turísticos del destino con diseños atractivos, aunque la rapidez de acceso a la información se ve afectada. En cuanto al empleo de herramientas y técnicas para el posicionamiento orgánico en los metabuscadores, los sitios de la competencia tienen posicionadas fundamentalmente los nombres de los principales destinos que promocionan, así como el nombre del país, que representa los mayores por cientos de tráfico hacia estos.

Todo lo anterior permitió constatar que el portal Cubatravel, que se encuentra en el dominio www.cuba.travel, no ajusta completamente su diseño web a las nuevas tendencias con respecto a las que sí se adaptan los sitios de la competencia. No presenta formatos de gran tamaño ni en texto ni en contenido multimedia, este último solo se limita a imágenes y videos, no existiendo audio en el portal. Por otra parte, sí se utiliza la bitonalidad con los colores azul, y rojo en menor medida sin llegar a ser colores brillantes. El mapa del sitio no permite acceder a los destinos, para ello es necesario dirigirse al sitio Cubamaps. Se observa el empleo de espacios en blanco, el diseño es responsive y cuenta con blog y chatbots, por lo que en este sentido su apariencia es aceptable, siempre y cuando se siga perfeccionando y ajustando a las novedades del mercado.

La velocidad de carga del portal Cubatravel se comparó con la de los sitios de la competencia, si bien ninguno de estos sitios tiene una velocidad de carga aceptable, al no cargar en menos de 5 segundos, la velocidad de carga de Cubatravel de 12.9 segundos sigue siendo mayor que la de la competencia; los sitios Bahamas.com, Colombia.travel y Godominicanrepublic.com cargan 1.4, 5.8 y 2.2 segundos, respectivamente, más rápido que Cubatravel, esto quiere decir que el portal Cubatravel debe seguir trabajando en optimizar la velocidad de carga, lo cual puede contribuir a mejorar su posicionamiento, aumentar el número de visitas e incluso reducir las tasas de rebote.

Se identificaron las palabras claves que generan tráfico hacia el portal Cubatravel, estas son: cuba, cuba turismo, la habana, turismo en cuba y turismo cuba, que representan aproximadamente un 41, 11, 9, 7 y 5 por ciento, respectivamente, de todas las búsquedas en el sitio. Estas palabras no se encuentran posicionadas por la competencia, representando una ventaja para Cubatravel que debe seguir trabajando en posicionarlas con contenidos digitales de calidad. Sin embargo, la herramienta utilizada identificó palabras claves populares que representan una oportunidad para que el sitio las posicione, en este caso, habana cuba, cienfuegos, matanzas cuba y trinidad cuba; las cuales se refieren fundamentalmente a destinos turísticos, aspecto que la competencia sí toma en consideración, por lo que resulta necesario su posicionamiento. 


\section{Evaluación de la calidad web del portal}

\section{- Análisis de Páginas de inicio}

Se analizaron los indicadores correspondientes al CODETUR, evidenciándose que el portal es un sitio web específico de turismo que se encuentra en 5 idiomas principales español, inglés, francés, alemán y ruso. En la página de inicio del sitio se presentan videos e imágenes que identifican al destino Cuba y esta tiene un apartado de contacto, sección de FAQS o ayuda al usuario, ofreciendo la posibilidad de registrarse. Aparecen iconos de las aplicaciones web 2.0 Twitter, Facebook, Youtube y Flickr, y se encuentran en la página los logotipos de las organizaciones encargadas de administrar el sitio, en este caso el MINTUR e Infotur, además del logotipo que representa la marca del destino Cuba.

Se consideró regular la existencia de una sección de noticias/agenda/eventos, puesto que en la página principal se promocionan los eventos y actividades más destacados en el momento que se navega, pero esta no cuenta con una agenda que permita acceder a otros eventos en diferentes períodos de tiempo. Lo mismo sucedió con el indicador del mapa web, porque independientemente que el sitio cuente con un mapa este no es interactivo, es más una imagen estática. En cuanto a la aparición de iconos de aplicaciones 2.0, estos solo aparecen al final de la página de inicio y no en otras zonas que puedan llamar la atención del usuario. No obstante, luego de promediados los resultados de la evaluación se determinó que el parámetro páginas de inicio se encuentra en el rango aceptable 0.75 $\leq \mathrm{x}<1.75$, según los rangos de valor que establece la Tabla 1 .

\section{- Análisis de Calidad y cantidad de contenido}

El contenido del portal Cubatravel no presenta grandes deficiencias según la evaluación realizada, puesto que se encuentra de acuerdo con la metodología del CODETUR en el rango aceptable $0.75 \leq x<1.75$ y Nibbler lo ubica en el rango óptimo de $8<x \leq 10$. En la evaluación asignada por la herramienta Nibbler se determinó que el sitio se encontraba en un estado óptimo ya que tiene una media de 777 palabras por página de las 1000 que se consideran adecuadas en un sitio web.

Se corroboró la existencia de información relativa a cómo llegar al destino desde las distintas vías de comunicación, al transporte, a monumentos, rutas turísticas e itinerarios; información sobre alojamientos y de interés general como teléfonos de la policía, bomberos, emergencia, ambulancia, hospitales o leyes del destino. Además de la información correspondiente a la historia, cultura y costumbres del destino, su oferta gastronómica y meteorología. Aparece el nombre de la organización encargada de la promoción del destino, todo lo referente a las oficinas de información turística y el contacto de la institución. El indicador más afectado fue en lo referente al contenido para personas con discapacidad, el sitio proporciona medios que ayudan en la navegación y localización del contenido como barras de navegación, mapas del sitio y buscadores, pero no se proporcionan alternativas textuales para cualquier contenido no textual, no existe contenido auditivo, ni sintetizadores de voz. 
- Análisis de Arquitectura de la información

En la metodología del CODETUR se encuentra en el rango aceptable, el portal presenta elementos de navegación que orientan al usuario como el buscador interno, que aparece en todas las páginas y se encuentra fácilmente; hace un buen uso del scroll, aprovechando las zonas de alta jerarquía informativa y presenta puntos de entrada visuales que captan la atención del usuario. Los títulos de las páginas son correctos y se utilizan etiquetas estándar. La evaluación del CODETUR que se muestra en la figura 1 permite identificar como el indicador enlaces reconocibles fue evaluado de regular, dada la existencia de enlaces del tipo "haga clic aquí". Además, se determinó que no es predecible la respuesta del sistema antes de hacer clic sobre los enlaces, puesto que no aparece información contextual, es decir, no se indica el formato y tamaño del documento o recurso con el que vincula el enlace.

\section{Evaluación de arquitectura de la información según el CODETUR}

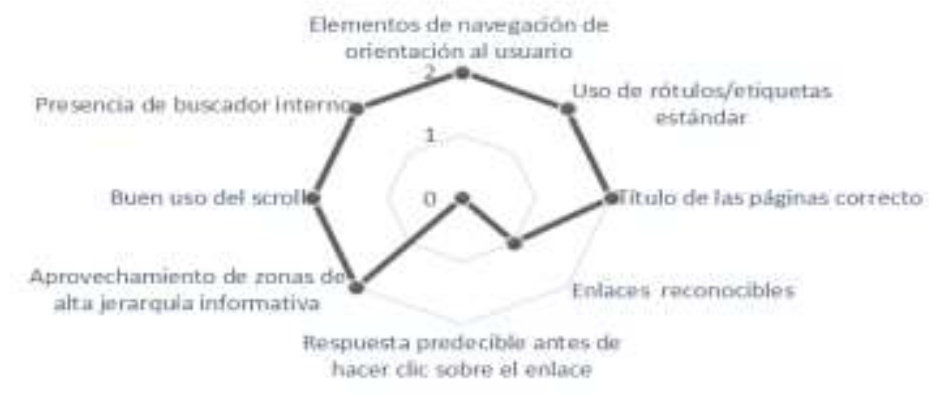

Figura 1. Evaluación del parámetro arquitectura de la información según la metodología de análisis CODETUR para la escala 0-1-2 (mal, regular, bien)

Fuente: Elaboración propia

Con respecto a las herramientas de análisis Nibbler y Woorank se determinó que el parámetro se encontraba en el rango aceptable $3 \leq \mathrm{x} \leq 8$ y óptimo $1.5 \leq \mathrm{x} \leq 2$ respectivamente. El indicador enlaces internos de Nibbler mostró que 5 enlaces se encontraban débilmente descritos ("haga clic aquí" o "leer más"), o sea, fallan en describir el contenido hacia el cual dirige el enlace lo cual pudiera contribuir a la optimización del sitio. El indicador títulos de páginas mostró que todas las páginas utilizaban los títulos correctamente y el indicador encabezados encontró que todas tienen encabezados definidos, aunque un 6 por ciento de forma incorrecta, no cumpliendo con la definición semántica que establece que las etiquetas de tipo H1 se utilizan para resumir el contenido de la página y las restantes etiquetas $\mathrm{H} 2, \mathrm{H} 3, \mathrm{H} 4$ etc. para dividir y resumir las diferentes secciones dentro del contenido.

La herramienta Woorank detectó un total de 121 enlaces, para un 11.8 y 88.2 por ciento de enlaces externos e internos respectivamente, lo cual es considerado correcto si se conoce que es recomendable limitar el número de enlaces a aproximadamente 200 por página. La herramienta descubrió 20.066 páginas en el portal, lo que significa que los 
robots son capaces de encontrar las páginas de la web y que la arquitectura es buena de manera general.

\section{- Análisis de Usabilidad y accesibilidad}

La evaluación con el CODETUR mostró que el sitio web se encuentra en un rango aceptable con un valor de 0.76, y guarda una apariencia formal integrada y coherente, utilizándose de forma clara una jerarquía visual para indicar las relaciones entre los diferentes elementos de las páginas. El texto se lee con claridad gracias al uso correcto de la tipografía y la adecuada disposición de interlineados y espaciados, así como una correcta longitud de línea. La fuente es lo suficientemente grande para no dificultar la legibilidad del texto y existe contraste entre esta y el fondo. Además, el usuario puede disfrutar de todos los contenidos del sitio web sin necesidad de tener que descargar e instalar plugins adicionales y se identifica rápidamente cuál es la OMD responsable, en este caso el MINTUR. No obstante, el sitio no brinda ayuda contextual en tareas complejas y no existe una sección de accesibilidad que informe al usuario de las normativas de accesibilidad del sitio.

Con respecto al cumplimiento de los requisitos de las pautas de accesibilidad, que establece el World Wide Web Consortium (W3C) en las Web Content Accessibility Guidelines WCAG 2.0, la web no se corresponde con ninguno de los niveles de adecuación establecidos A/AA/AAA, lo que se comprobó a través de la herramienta Cynthia Says que mostró que los videos no poseen audio ni texto o subtitulos y el portal no presenta en la mayoría de los casos atributos de texto alternativo "alt" y "title", es decir, no se describe el propósito de las imágenes y enlaces con texto alternativo, aspecto fundamental para aparecer en los resultados de búsqueda de Google y proporcionar un contexto a las personas con discapacidad visual.

Nibbler lo sitúa en el rango aceptable $8<\mathrm{x} \leq 10$, la herramienta detectó que las imágenes no tienen una resolución establecida, y en el comportamiento del servidor el sitio web no fue servido usando codificación GZIP, herramienta de compresión de datos fundamental en la reducción del tiempo de carga de las páginas webs. Woorank lo ubica dentro del rango óptimo $1.5 \leq \mathrm{x} \leq 2$, la evaluación realizada detectó que 18 de las 81 imágenes encontradas no presentan atributo "alt" o texto alternativo. La calidad de las imágenes se consideró regular, para ello se tomaron en cuenta los criterios de evaluación de la herramienta GT Metrix que demostró que las imágenes no se encontraban optimizadas.

\section{- Análisis de Posicionamiento}

El parámetro según el CODETUR se encuentra en un rango óptimo $1.75 \leq \mathrm{x} \leq 2$; el sitio aparece entre los 10 primeros resultados orgánicos en búsquedas con las palabras clave "turismo" y "Cuba". Según la herramienta Nibbler este se encuentra en el rango óptimo $8<\mathrm{x} \leq 10$, siendo el sitio 713.946 más popular del mundo, asimismo, existen 281.907 páginas en 1.733 dominios con enlaces al portal Cubatravel. Todas las páginas incluyen metadatos, pero solo el $80 \%$ de estas presentan meta etiquetas, las cuales, si no se incluyen, Google elige una muestra del texto de la página de manera aleatoria para 
aparecer en el resultado de búsqueda. Woorank ubica este parámetro en un rango óptimo, identificándose 257.494 backlinks o enlaces de retorno, que son vistos como cartas de recomendación para la web. La etiqueta de título y la meta descripción son correctas y cuenta con seguridad SSL (HTTPS), el tráfico hacia esta web es medio, siendo la 782.780 web más visitada del mundo.

Se aprecia que las herramientas Nibbler y Woorank no ubican el portal Cubatravel en el mismo puesto del ranking de los sitios con mayor tráfico y por tanto más populares, puesto que los resultados de las herramientas online son aproximaciones de la realidad, no obstante, se evidencia que el sitio se encuentra en el orden de los 800 mil sitios mejor posicionados. Se conoce por medio de la herramienta Google Analytics que el sitio recibió el pasado 2019 alrededor de 3.942 .733 visitas a páginas con un promedio de tiempo de 33 segundos en las mismas y un porcentaje de rebote de 6.17\%. Ese mismo año se recibieron 902.738 usuarios con 1.19 sesiones por usuario con una duración media de 1 minuto y 29 segundos.

\section{- Análisis de Idiomas}

La herramienta Woorank determinó el parámetro en un rango óptimo $1.5 \leq \mathrm{x} \leq 2$, especificándose el idioma del sitio web como español. Por su parte, el CODETUR identifica el parámetro idiomas en el rango aceptable con un valor de 0.8 . Los indicadores más afectados de la evaluación realizada a través del CODETUR son la adaptación cultural del sitio por países y el reconocimiento automático de la procedencia, su evaluación se corroboró con los criterios de la especialista en la administración del portal Yasmina Giro. Se consideró que las páginas del sitio en otros idiomas son más bien una traducción desde el español, no adaptándose a la cultura de los países que defienden dichos idiomas.

\section{- Análisis de Tratamiento de la marca}

El parámetro tratamiento de la marca según la evaluación asignada por la metodología del CODETUR que se muestra en la figura 2, se encuentra en un rango aceptable $0.75 \leq$ $\mathrm{x}<1.75 \mathrm{y}$ con respecto a la herramienta Woorank en un rango óptimo $1.5 \leq \mathrm{x} \leq 2$. Entre los principales indicadores afectados se encuentra la no existencia de un eslogan en la página principal, ni de una descripción de los valores de la marca, a partir de los cuales es posible construir una cultura de marca propia, del mismo modo que identificar un propósito capaz de generar confianza. Además, no existen historias, relatos o mitos que se asocien o cuenten sobre la marca lo que es conocido como stroytelling, técnica que consiste en establecer un vínculo emotivo con el usuario, forzándolo a prestar atención a la historia en lugar del producto. La herramienta Woorank determinó que la URL cuba.travel es correcta, la cual tiene una longitud de 4 caracteres, con el dominio travel asociado a viajes y turismo. El sitio web utiliza una pequeña imagen para identificar de una forma más sencilla las páginas conocida como favicon. 


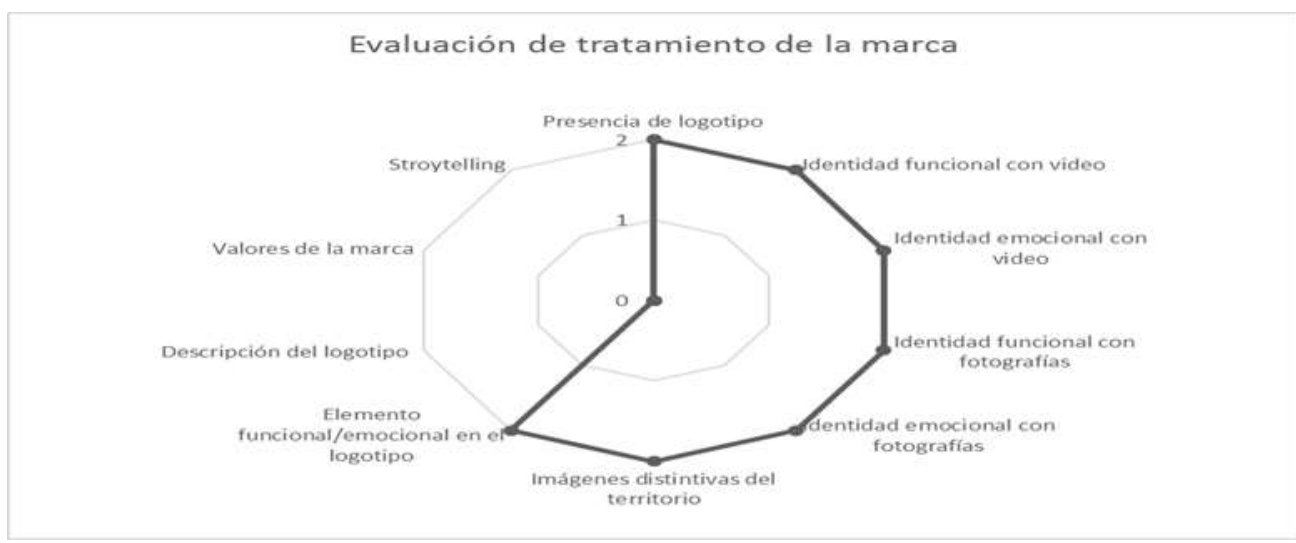

Figura 2. Evaluación del parámetro tratamiento de la marca a través del CODETUR en su escala 0-1-2 (mal, regular, bien)

Fuente: Elaboración propia

- Análisis de interactividad

El parámetro interactividad según la evaluación asignada por el CODETUR, que se muestra en la figura 3, se encuentra en un rango crítico $x<0.75$, esto se debe principalmente a que el portal no permite al usuario votar o comentar los contenidos, la interacción es solo a través del blog y las redes sociales, tampoco se incluyen en este, historias, experiencias o comentarios de los usuarios; lo cual trae consigo que el portal no se adapte, en este sentido, a las necesidades del llamado turista 2.0 quien necesita de los comentarios de otros viajeros y emitir propios para alcanzar un nivel de confiabilidad y sentirse seguro en el sitio visitado.

La no existencia de un planificador de viaje, tours virtuales, y recursos interactivos como mapas y música, afecta también al sitio, siendo estas últimas, herramientas muy demandas por los usuarios en la actualidad. Independientemente que el parámetro se encuentre en un estado crítico, existen indicadores que, si se cumplen como, la existencia de videos promocionales sobre el destino, la posibilidad de descargar folletos turísticos y planos, así como aplicaciones móviles. Además de la existencia de un chat para atender las inquietudes de los usuarios.

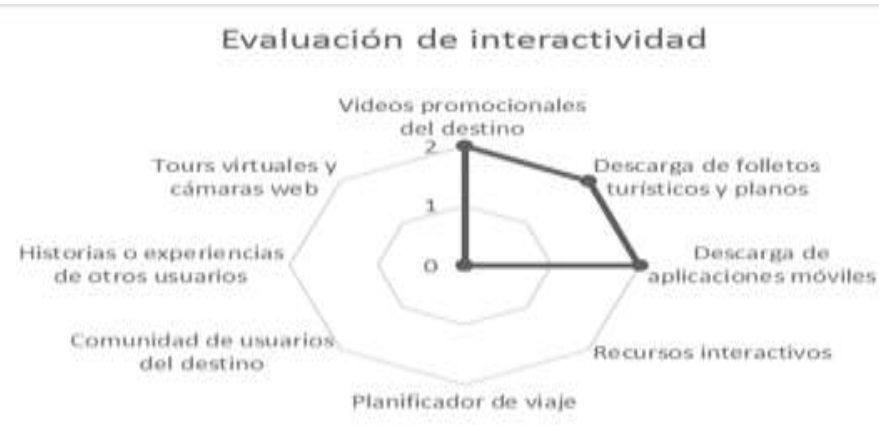

Figura 3. Evaluación del parámetro interactividad de acuerdo con el CODETUR Fuente: Elaboración propia 
- Análisis de web social

El parámetro web social se encuentra en un rango aceptable con un valor de 1.25 de acuerdo con el CODETUR. La evaluación realizada evidenció que el sitio permite suscribirse para acceder a los contenidos, pero de manera general y no por temática de preferencia. Para la publicación de fotografías solamente se emplea Flickr, y para difundir las informaciones solo se usa Twitter, además de no utilizarse TripAdvisor para que los usuarios hagan recomendaciones sobre la información que se ofrece.

Nibbler ubica el parámetro en el rango crítico $\mathrm{x}<3$, esto se debe a que la herramienta mide el indicador interés social solo analizando las cuentas de Google + y Facebook, el portal no presenta cuenta de Google + y Nibbler no detectó "me gusta" a la página de Facebook en las 5 páginas analizadas. Woorank sitúa el parámetro en un rango óptimo $1.5 \leq \mathrm{x} \leq 2$, la herramienta detectó que no existe una cuenta en Instagram y que el portal es popular en la red social Facebook, siendo compartido 2692 veces, con 5965 "me gusta" y 296 comentarios. Además, se encontraron etiquetas de protocolo open graph, que permiten controlar como se presentan las páginas de un sitio web cuando se comparten a través de las redes sociales.

\section{- Análisis de comunicación móvil}

Según el CODETUR las principales afectaciones se encontraron en las funciones de la aplicación, al no encontrarse en esta audioguía, videoguía, compartir comentarios, galería de imágenes, geocalización, información de agenda, promoción y descuentos, realidad aumentada y valoración de lugares. Nibbler ubica el parámetro en el rango óptimo $8<$ $\mathrm{x} \leq 10$ al igual que Woorank $1.5 \leq \mathrm{x} \leq 2$, aunque esta última identificó dificultades con el indicador pantalla táctil. La herramienta Woorank determinó que los enlaces y botones de la página son demasiado pequeños o están demasiado juntos para poder usarlos en un dispositivo móvil. En el indicador tamaño de fuente la herramienta detectó que el texto de la página web es legible en un dispositivo móvil, al menos el $60 \%$ del tamaño de fuente de la página tiene 12 píxeles o más.

\section{- Análisis de velocidad de carga y tamaño de páginas}

El parámetro se encuentra en el rango crítico $\mathrm{x}<0.5$ de acuerdo con la herramienta Woorank. En el indicador minificación de recursos se detectó que se puede reducir 432,7 $\mathrm{Kb}$ que representan un $37 \%$ de los recursos, lo cual reduce el tamaño de transferencia y hace que se envíen menos bytes a través de la red, cargándose el sitio web con mayor velocidad. La herramienta encontró un total de 5 recursos no almacenados en caché. Para el análisis del tiempo de carga y el tamaño de páginas con la herramienta GT Metrix se realizaron 4 análisis de cada indicador y se determinó la media de los resultados, obteniéndose que en el primer indicador el parámetro se encuentra en el rango crítico $\mathrm{x}>$ 5 , al igual que en el segundo $x>3$, dado que la web tarda 12.9 segundos en cargar y tiene un peso de $22 \mathrm{Mb}$. La herramienta detectó problemas en la minimización de archivos JavaScript, HTML y CSS. 


\section{Resultados del diagnóstico}

Los resultados de las dos fases del diagnóstico realizado permitieron identificar los factores que están incidiendo en la insatisfacción de los usuarios con respecto al portal de turismo Cubatravel para la promoción del destino Cuba, los cuales se muestran en la figura 4. La primera fase identificó la velocidad de carga del sitio como una de las principales dificultades, así como la necesidad de posicionar palabras claves relacionadas con los nombres oficiales de los diferentes destinos turísticos del destino Cuba. La segunda fase determinó que el 72 por ciento de los parámetros evaluados se encontraba en un estado aceptable para solo un 18 por ciento en estado crítico. El único parámetro considerado óptimo fue posicionamiento, donde se obtuvieron resultados positivos en los 15 indicadores evaluados, entre los más relevantes se puede destacar que el portal se encontraba entre los 10 primeros resultados orgánicos en búsquedas.

En la figura 4 se observa como la información no llega al usuario de manera inmediata dadas las afectaciones en la velocidad de carga y el tamaño de páginas, por lo que se corre el riesgo de que este abandone el sitio antes de interactuar con él; para contrarrestar esta situación se recomienda reducir recursos y almacenarlos en caché. Los problemas de accesibilidad y usabilidad no permiten captar aquellos segmentos de demanda con discapacidad visual y auditiva. No se aprovecha la tecnología de geolocalización, pudiendo perderse usuarios de otras culturas que no se sientan identificados con el contenido del sitio, incidiendo negativamente en la posibilidad de usar códigos coherentes a los públicos meta por lo que se requiere personalizar los mensajes. El hecho de no emplear el stroytelling o de no describir los valores de la marca afecta la finalidad del sitio de captar la atención del usuario e influir en su decisión, e incluso la imagen que este se lleva del destino turístico, puesto que no se logra una diferenciación del destino con respecto a la competencia. Es por ello que se necesita identificar un propósito capaz de generar confianza y establecer un vínculo emotivo con el usuario. Las afectaciones en los calendarios, mapas web y enlaces, dificultan la navegación de los usuarios y restan atractividad al sitio.

Asimismo, los problemas con la comunicación móvil van en contra de las necesidades del nuevo turista que prioriza el empleo de teléfonos inteligentes, por lo que se deben espaciar los elementos pinchables para que el dedo del usuario que está seleccionando un elemento no seleccione sin querer otro, además de rediseñar la aplicación web. El no contar con comentarios y experiencias de viajeros afecta la credibilidad del sitio ante el nuevo turista que se encuentra fuertemente influenciado por la percepción de otros usuarios, por lo que se precisaría permitir al usuario generar contenido en el sitio, compartiendo sus vivencias y recomendaciones. Además, la ausencia de tours virtuales y elementos interactivos no permite que el usuario se entretenga en los momentos de búsqueda, se incline a hacer compras por impulso al contemplar atractivos turísticos, o que viva la experiencia previa del destino que va o desea visitar, por lo que el sitio no es efectivo en este sentido. 


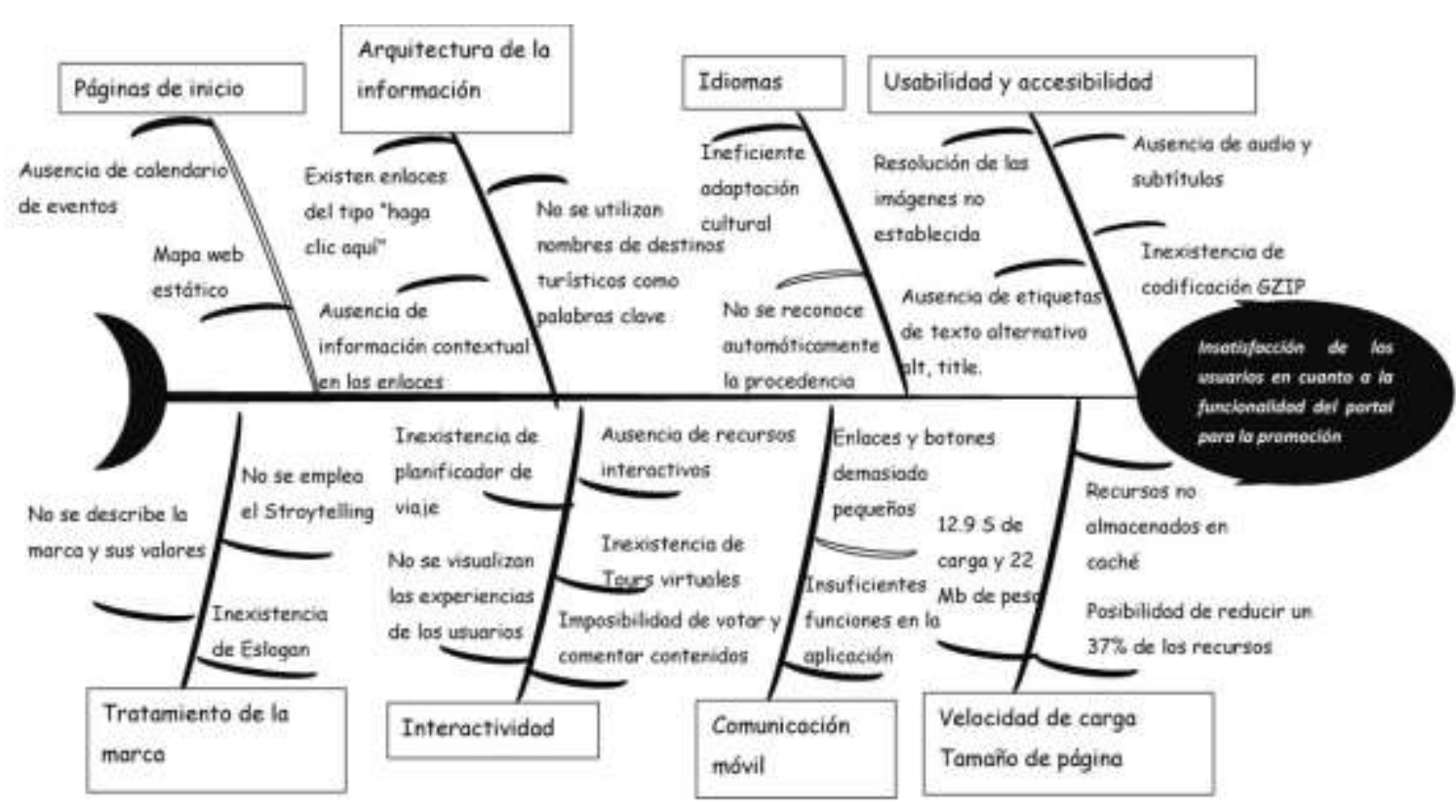

Figura 4. Diagrama de Ishikawa

\section{Conclusiones}

- Los sitios web o portales oficiales de los destinos turísticos son esenciales para el desarrollo de una imagen de los destinos basada en la promoción turística, la cual proporciona a los consumidores el conocimiento de los atractivos y de la infraestructura existente diferenciando el destino de la competencia, inspirando confianza y credibilidad.

- El diseño metodológico de la investigación combinó la metodología de análisis del proyecto comunicación online de destinos turísticos CODETUR con herramientas de análisis web como, Woorank, Gt Metrix, Alexa, Nibbler, Site worth Traffic, Cynthia Says y Alexa Rank Checker Sinium para determinar la correspondencia del portal Cubatravel con las mejores prácticas en diseño web de destinos del Caribe, así como su calidad web.

- Los principales factores que inciden en la insatisfacción de los usuarios con respecto a la funcionalidad del portal para la promoción del destino Cuba son: el diseño de las páginas de inicio, la arquitectura de la información, la usabilidad y accesibilidad, los idiomas, el tratamiento de la marca, la interactividad, la comunicación móvil y la velocidad de carga - tamaño de página.

- El portal de turismo Cubatravel requiere posicionar palabras clave que se correspondan con los nombres oficiales de los diferentes destinos turísticos, disminuir su velocidad de carga y tamaño de páginas, además de mejorar su interacción con los usuarios para alcanzar la confianza de los mismos.

\section{Referencias Bibliográficas}


Anagrama. (2019). Stroytelling, el arte de contar historias en publicidad. Obtenido de Anagrama Comunicación $\mathrm{y}$ Marketing: http://anagramacomunicacion.com/publicidad/storytelling-el-arte-de-contarhistorias/

Araujo, N., Cardoso, L., \& De Araujo, A. (2019). La comunicación 2.0 en el sector turístico español: análisis de las webs oficiales de promoción turística. International Journal of Marketing, Communication and New Media.

Cáceres, M. (2016). Análisis de la calidad de las páginas web de los hoteles de 5 estrellas de Madrid. Sevilla.

Caraguay, P. (2019). Estrategias de promoción turística para la potenciación de la Isla Santa Clara en destino ecoturístico. Machala: Facultad de Ciencias Empresariales.

Castelluci, D. (2007). Aplicación de las TICs en la promoción de destinos. Aportes y Transferencias, 11(1), 43-60.

Castillo, A., Carrillo, M., \& Luengo, G. (2019). La comunicación de la marca de las cadenas hoteleras a través de sus sedes web: propuesta de un modelo para su gestión. Palabra Clave, 22(2).

Castillo, M., \& Castaño, V. (2015). La promoción turística a través de técnicas tradicionales y nuevas. Una rrevisión de 2009 a 2014. Estudios y perspectivas en Turismo, 24, 755-775.

Cobeña, T., Zambrano, T., \& Pinargote, M. (2019). Análisis de normas de accesibilidad web en el sitio web de la Facultad de Informática de la Universidad Laica "Eloy Alfaro" de Manabí. Revista de tecnologías de la informática y las telecomunicaciones, 23-31.

Córdova, J., \& Freixa, P. (2017). Turismo, web 2.0 y comunicación interactiva en América Latina. Buenas prácticas y tendencias. International Journal of Information Systems and Tourism (IJIST).

Daries, N., Fransi, E., \& Martín, E. (2014). Promoción turística de las comunidades autonómas españolas a través de las redes sociales. Papers de Turisme(55), 84106.

Díaz, P., \& Jimenez, G. (2013). La web como herramienta de comunicación y distribución de destinos turísticos. Análisis y modelos. Sevilla: Universidad de Sevilla.

Díaz, P., \& López, B. (2012). La promoción turística oficial en Internet y su relación con el desarrollo turístico de los destinos: Una aplicación a las ciudades medias de Andalucía. Revista de Estudios Regionales(93), 93-115. 
Domínguez, T., \& Araujo, N. (2014). Gestión de las redes sociales turísticas en la web 2.0. Vivat Academia, Revista de Comunicación, 129, 57-78.

Estevez, J. (2012). Las páginas web de los países de América Latina: una aproximación a la web 2.0 en los destinos turísticos latinoamericanos. Revista de Investigación en Turismo y Desarrollo Local, 5(13).

Fernández, J., Díaz, P., \& Huertas, A. (2013). Marcas de Destino y Evaluación de sitios web: una metodología de invetigación. Revista Latina de Comunicación Social(068), 622-638.

Fernández, J., Rovira, C., \& Gómez, L. (2010). Propuesta de diseño de una plantilla multidisciplinar para el análisis y evaluación de webs de destinos turísticos. VIII Congreso "Turismo y Tecnologías de la Información y las Comunicaciones" Turitec.

Fernández, J., Vinyals, S., \& López, M. (2013). Calidad de los sitios web turísticos oficiales de las comunidades autónomas españolas. Barcelona.

Foradada, C., \& Irala, P. (2019). Arte, patrimonio y tecnología en la era digital. Gobierno de Aragón: Universidad Zaragoza.

García, L. (2019). Tendencias en diseño web 2019: lo que viene para quedarse. Obtenido de 40deFiebre: https://www.40defiebre.com/tendencias-diseno-web

García, M. (18 de agosto de 2014). Cuenta la historia de tu marca. Obtenido de Entrepreneur: https://www.entrepreneur.com/article/267290

Gondim, F., De Moura, J., \& Lucirton, A. (2012). Brazil's image abroad: how can the public and private sector partnership improve marketing strategies. Tourism Planning \& Development, 10(1), 110-119.

Gónzalez, C. (2018). Análisis del sitio web "Guayaquil es mi destino" bajo parámetros de calidad del CODETUR para diseñar estrategias de mejora. Ecuador: Universidad de Guayaquil.

Jiménez, L., Pérez, M., \& Sánchez , L. (2017). Diseño de información digital: revisión y clasificación de indicadores heurísticos para contenidos web. Barcelona: Departamento de Biblioteconomía, Documentación y Comunicación Audiovisual.

Kim, H., \& Fesenmaier, D. (2008). Persuasive design of destination web sites: An analysis of first impression. Journal of Travel Research, 47(3), 3-13.

Martínez, A. (2018). Marketing 2.0 aplicado al sector turístico: la función comercial de los sitios webs de las organizaciones de marketing de destinos. Vivat Academia. Revista de Comunicación(143), 01-23. 
Martínez, A., Monserrat, J., \& Campillo, C. (2017). El paradigma relacional en las estrategias de las organizaciones de marketing de destinos. Interactividad y función social en las webs turísticas oficiales. Revista Latina de Comunicación Social, 374-396.

Mendes, G., Biz, A., \& Gandara, J. (2013). Innovación en la promoción turística en medios y redes sociales. Estudios y Perspectivas en Turismo, 22, 102-119.

Miralbell, O. (2001). Portales de Destinos Turísticos en Internet: Una reflexión estratégica. Barcelona: Escuela Universitaria de Turismo, Universidad Autonóma de Barcelona.

Ogra, A. (2014). Tourism Web Analytics- A case of study of Garhwal and Kumaon Regions of Uttarakhand, India. University of Johannesburg.

Ortiz, Y. (2019). Accesibilidad en sitios web del Ministerio de Educación de Chile. Chile: Universidad de Los Lagos.

Palmira, E. (2019). Marketing de Turismo para el posicionamiento de Puerto López de la provincia de Manabí como destino turístico. Guayaquil: Facultad de administración.

Pavón, P. (2018). Buenas prácticas para el desarrollo digital del destino turistico cubano. Revista Cubana de Administración pública y empresarial.

Perez, E. (14 de noviembre de 2018). 12 tendencias de diseño web para 2019. Obtenido de Avanza Soluciones de Comunicación: https://www.saulverez.com/12tendencias-en-diseno-web-para-2019-ejemplos/

Perurena, L., \& Moráguez, M. (2013). Usabilidad de sitios web, los métodos y las técnicas para la evaluación. Revista Cubana de Infromación en Ciencias de la Salud, 24(2), 176-194.

Roche, A. (2019). El modelo de negocios online para las agencias de viaje de la OSDE Viajes Cuba. La Habana: Facultad de Turismo.

Ruiz, I. (2 de enero de 2019). Tendencias en diseño web para este 2019. Obtenido de Webempresa: https://www.webempresa.com/blog/tendencias-diseno-web2019.html

Ruiz, P. (18 de noviembre de 2019). Cómo medir y mejorar la velocidad de carga de tu página web. Obtenido de Diseño web: https://www.lomejordewp.com/medirmejorar-velocidad-carga-pagina-web/

Salgado, J. (2009). Sitios web de cara al consumidor en destinos y grupos turísticos nacionales. En J. Salgado, El negocio electrónico en el turismo (págs. 149-163). La Habana: Félix Varela. 
Sanabre, C., Pedraza, R., \& Codina, L. (2018). WebSite Canvas Model: propuesta de un modelo visual para la ideación estratégica de sitios web. Revista Española de Documentación Científica, 41(4).

Sanabre, C., Vinyanls, S., \& Pedraza, R. (2019). Calidad de los sitios web de los destinos turísticos: El caso del DTI Barcelona. Barcelona: Departamento de Comunicación, Universitat Pompeu Fabra.

Sánchez, E., Martínez, V., \& Juanatey, O. (2019). Redes sociales y promoción de destinos turísticos termales de la Eurorregión Galicia-Norte de Portugal. Observatorio Journal, págs. 137-152.

Suau, F. (2012). El turista 2.0 como receptor de la promoción turística: estrategias lingüísticas e importancia de su estudio. Pasos, Revista de Turismo y Patrimonio Cultural. Pasos, Revista de Turismo y Patrimonio Cultural, 10(4), 143-153.

Tapia, M. (2015). Factores de calidad en sitios web de destino turístico: estado de la cuestión.

Torrado, G., \& Blanco, R. (2018). Uso de Internet y redes sociales para la práctica turística. Caso de Extremadura. Asociación Extremeña de Sociología (ACISE).

Túñez, M., Altamirano, V., \& Valarezo, K. (2016). Comunicación turística colaborativa 2.0 : promoción, difusión e interactividad en las webs gubernamentales de Iberoamérica. Revista Latina de Comunicación Social(71), 249-271.

Verdecia, A. (2018). Tendencias del consumidor digital para el producto turístico. Revista Granmense de Desarrollo Local, 2(3).

Villalobos, C. (8 de julio de 2019). 15 tendencias en diseño web que no debes perder de vista 2019.2 Obtenido Hubspot: https://blog.hubspot.es/marketing/tendencias-diseno-web

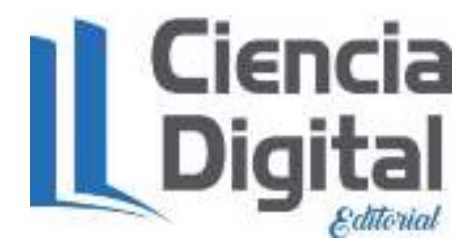




\section{PARA CITAR EL ARTÍCULO INDEXADO.}

Calderín Mayo, Y., \& Velastegui López, L. E. (2021). Diagnóstico de la situación del portal de turismo Cubatravel para la promoción del destino Cuba. AlfaPublicaciones, 3(3.2), 30-50. https://doi.org/10.33262/ap.v3i3.2.96

\section{LCiencia}

El artículo que se publica es de exclusiva responsabilidad de los autores y no necesariamente reflejan el pensamiento de la Revista Alfa Publicaciones.

El artículo queda en propiedad de la revista y, por tanto, su publicación parcial y/o total en otro medio tiene que ser autorizado por el director de la Revista Alfa Publicaciones.
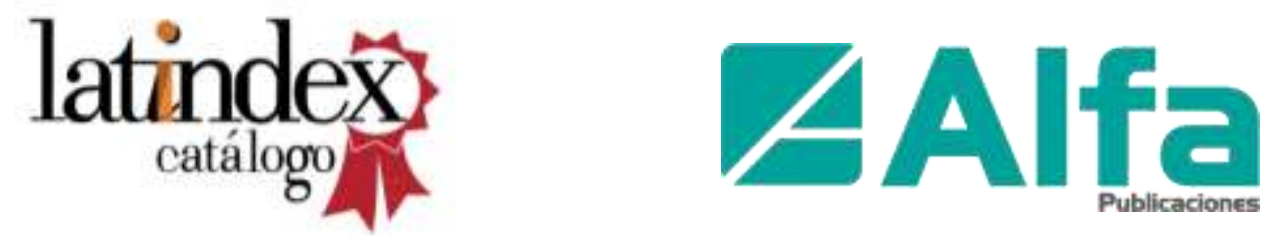